\title{
OsNAC300 Positively Regulates Cadmium Stress Responses and Tolerance in Rice Roots
}

\author{
Shubao Hu ${ }^{1}$, Kamran Iqbal Shinwari ${ }^{1}$ D, Yuxinrui Song ${ }^{1}$, Jixing Xia ${ }^{2} \mathbb{D}$, Heng Xu $^{1}$, Binbin Du $^{1}$, Le Luo ${ }^{3}$ \\ and Luqing Zheng ${ }^{1, *(\mathbb{D})}$ \\ 1 College of Life Sciences, Nanjing Agricultural University, Nanjing 210095, China; \\ Shubao_hu@njau.edu.cn (S.H.); 2016216033@njau.edu.cn (K.I.S.); 2017116047@njau.edu.cn (Y.S.); \\ 2019816148@njau.edu.cn (H.X.); 2017216004@njau.edu.cn (B.D.) \\ 2 State Key Laboratory for Conservation and Utilization of Subtropical Agro-Bioresources, \\ College of Life Science and Technology, Guangxi University, Nanning 530005, China; xiajx@gxu.edu.cn \\ 3 College of Resources and Environmental Sciences, Nanjing Agricultural University, Nanjing 210095, China; \\ luole@njau.edu.cn \\ * Correspondence: zhenglq@njau.edu.cn; Tel.: +86-25-8439-5423
}

Citation: Hu, S.; Shinwari, K.I.; Song,

Y.; Xia, J.; Xu, H.; Du, B.; Luo, L.;

Zheng, L. OsNAC300 Positively

Regulates Cadmium Stress Responses and Tolerance in Rice Roots.

Agronomy 2021, 11, 95.

https://doi.org/10.3390/

agronomy11010095

Received: 3 December 2020

Accepted: 2 January 2021

Published: 6 January 2021

Publisher's Note: MDPI stays neutral with regard to jurisdictional clai$\mathrm{ms}$ in published maps and institutional affiliations.

Copyright: $\odot 2021$ by the authors. Licensee MDPI, Basel, Switzerland. This article is an open access article distributed under the terms and conditions of the Creative Commons Attribution (CC BY) license (https:// creativecommons.org/licenses/by/ $4.0 /)$.
Abstract: Transcriptional regulation is involved in responding to cadmium (Cd) stress in plants. However, the molecular mechanisms of $\mathrm{Cd}$ stress responses regulated by transcription factors remain largely unknown in plants. In this study, a rice (Oryza sativa) NAC (no apical meristem [NAM]; Arabidopsis transcription activation factor [ATAF]; cup-shaped cotyledon [CUC]-related) family transcription factor, OsNAC300, was isolated and functionally characterized for its involvement in Cd stress responses and tolerance. OsNAC300 was localized to the nucleus. OsNAC300 was mainly expressed in roots and significantly induced by $\mathrm{Cd}$ treatment. Knockout of OsNAC300 resulted in increased sensitivity to Cd stress, while its overexpression lines enhanced tolerance to Cd stress. RNA-Seq analysis revealed that the mutant is impaired in regulating some important genes that were responsive to $\mathrm{Cd}$ stress in wild-type rice, such as the pathogenesis-related genes 10a (OsPR10a), OsPR10b, chalcone synthase 1 (OsCHS1), and several others, which was validated by reverse transcription quantitative polymerase chain reaction (RT-qPCR) analysis. Moreover, chromatin immunoprecipitation-qPCR assays and luciferase reporter assays demonstrated that OsNAC300 directly binds to the promoters of OsPR10a, OsPR10b, and OsCHS1 and activates their transcription. Overall, OsNAC300 is an important regulatory factor in Cd stress responses and tolerance in rice.

Keywords: cadmium; OsNAC300; rice (Oryza sativa); stress; RNA-Seq; OsPR10a; OsCHS1

\section{Introduction}

Cadmium (Cd) is a highly toxic metal element to almost all organisms, including humans and plants [1,2]. Anthropogenic activities such as mining and smelting, and modern agricultural practices including overusing fertilizers and herbicides/pesticides have led to increased $\mathrm{Cd}$ contamination in the environment, which poses a serious threat to human health [3]. Rice (Oryza sativa L.) is the most important staple cereal crop for most Asian countries and can accumulate a high $\mathrm{Cd}$ level in its grains [4]. Excess Cd can also affect plant growth and development via the disruption of nutrient homeostasis, dysfunction of proteins, and the generation of toxic reactive oxygen species (ROS) [5]. Several defense mechanisms against $\mathrm{Cd}$ stress have been identified in plants and other organisms, including chelation, extrusion, sequestration of $\mathrm{Cd}$, and the removal of $\mathrm{Cd}$-triggered ROS, for example, cys-rich proteins or peptides such as metallothionein, phytochelatin (PC), and defensin-like protein, are often used to chelate heavy metal $\mathrm{Cd}$ and are involved in $\mathrm{Cd}$ stress tolerance in plants [6-8].

The content of ROS in plant cells rapidly increases upon heavy metal Cd stress [9]. In addition, stress-responsive flavonoids have substantial potential to inhibit the generation 
of ROS and reduce ROS levels, i.e., flavonoids act as antioxidants. Chalcone synthase (CHS) is the rate-limiting enzyme in the flavonoid synthesis pathway in Petunia hybrida [10]. The expression of CHS has been induced in various plant species under different forms of stress, such as UV, wounding, herbivory, and microbial infections (reviewed in Dao et al. [11]). These findings implied the potential role of flavonoids as antioxidants to remove ROS generated under $\mathrm{Cd}$ stress in plants.

Pathogenesis-related (PR) proteins are highly conserved proteins that have been well defined; these can quickly respond to biotic and abiotic stresses, including pathogen infection, wounding, drought, high salinity, and heavy metal toxicity [12]. The major families of PRs have been divided into 17 classes (PR1 to PR17), primarily based on their amino acid sequence identity and biological activities [13]. Among these, PR10 proteins are typically intracellular, small $(16-19 \mathrm{kDa})$, and acidic, with similar three-dimensional structures [14]. PR10 proteins have been reported to have various functions, such as antimicrobial, ribonuclease, and norcoclaurine synthase activities, and the ability to bind ligands [14-16]. Some studies also revealed that the PR10 genes are responsive to various environmental stresses, such as drought, high salinity, low and high temperatures, wounding, and UV exposure [17]. There are four PR10 genes, OsPR10a, OsPR10b, RSOsPR10 (rootspecific PR 10), and JIOsPR10 (jasmonic acid-inducible PR 10) in the rice genome [18-20]. OsPR10a and OsPR10b encode predicted proteins of 158 and 160 amino acids, respectively, and share 71\% amino acid identity [18]. OsPR10a (encodes PBZ1) was first characterized as a probenazole-inducible protein in rice [21]. OsWRKY6 directly regulates the expression of OsPR10a, since WRKY transcription factors are known to be transcriptional activators of $P R$ genes [22]. Rice and bentgrass (Agrostis spp.) that overexpressed RSOsPR10 displayed improved tolerance to drought (rice and bentgrass) and salt (bentgrass) [17]. Overexpression of JIOsPR10 enhances the tolerance to biotic and abiotic stress in rice [12]. The expression of pathogenesis-related class 5 (OsPR5) was induced in leaves of rice that were wounded and upregulated by salicylic acid (SA), jasmonic acid (JA), and kinetin and protein phosphatase (PP) 2A inhibitors [23]. However, whether PR proteins respond to Cd stress and/or are involved in plants' tolerance to $\mathrm{Cd}$ stress have not been reported.

Transcriptional regulation is extensively involved in the response of plants to signal molecules in the external environment, such as biotic and abiotic stresses. The expression of many genes responds to biotic and abiotic stress in plants, including genes encoding transcription factors (TFs) and defense-related proteins [24,25]. The NAC (NAM, no apical meristem; ATAF, Arabidopsis transcription activation factor; CUC, cup-shaped cotyledon) domain TFs include a plant-specific gene family with few members that has been studied for its roles in plant growth and biotic/abiotic stress tolerance across various plant species [26]. More than 151 rice NAC (ONAC) TFs have been identified, but only a few of these have been functionally defined [27,28]. Yuan et al. [29] specified that ten ONAC genes exhibit pivotal functions in rice response to abiotic stress tolerance. The ten genes are ONAC002, ONAC003, ONAC009, ONAC022, ONAC045, ONAC048, ONAC058, ONAC066, ONAC095, and ONAC122.

A large number of TFs cooperate to complete the specific regulation of downstream functional genes, thereby improving the ability of plants to adapt to fluctuations in the external environment [30]. It is difficult for plant roots to avoid detrimental substances in the soil, such as $\mathrm{Cd}$ and aluminum (Al), and plants must have a set of transcriptional regulatory mechanisms to manage such toxicities. In plant, for the regulatory responses to $\mathrm{Cd}$ stress, studies of a few TFs, such as OsMYB45, AtZAT6, TaHSFA4a, and CaPF1, have been reported, since these TFs facilitate the tolerance of plants to $\mathrm{Cd}$ stress by improving their antioxidant capacity, metallothionein expression, and content of glutathione (GSH) [31-34]. Comparative transcriptome analysis under $\mathrm{Cd}$ stress has shown that there are still many unreported genes that are strongly induced by Cd stress [35-37]. This indicates that many unknown TFs are involved in the process of regulating plant cells in response to $\mathrm{Cd}$ stress.

In our previous study, several TFs that increased in expression after $\mathrm{Cd}$ stress were identified in rice [35]. To characterize these regulators that function in the response to $\mathrm{Cd}$ 
stress, we performed phenotypic screening based on the mutants of these TFs and found that OsNAC300 (also designated ONAC300/OsNAC077); (Os12g0123800/LOC_Os12g03050) may play an important role in response to Cd stress in rice. Kusano et al. [38] had shown that high levels of OsNAC300 mRNA were detected by in situ hybridization in the developing shoot apical meristem (SAM) and in young leaves, however, the biological function of OsNAC300 is unknown. Here, we show that OsNAC300 plays an important regulatory role in $\mathrm{Cd}$ stress responses and $\mathrm{Cd}$ tolerance in rice.

\section{Materials and Methods}

\subsection{Plant Materials and Growth Conditions}

Three osnac300 knockout lines were generated by editing OsNAC300 in the "Nipponbare" background. One target sequence (gRNA1, 257-276 bp; Supplemental Table S1) for CRISPR/Cas9 was used from the genomic sequence of OsNAC300 and inserted into the CRISPR/Cas9 vector pRGEB31 (Addgene, Watertown, MA, USA) [39]. The risk of off-target mutations was minimized by the selection of highly specific target sequences via a thorough genome search (www.genome.arizona.edu/crispr/). Agrobacterium-mediated transformation was performed using vigorously growing calluses derived from mature rice embryos [40]. Homozygous lines were confirmed by sequencing PCR-amplified products from potential mutant plants.

To generate the OsNAC300 overexpression (OE) lines, the full-length OsNAC300 cDNA sequence was amplified using the primer pairs (Supplemental Table S1). The amplified cDNA fragment was digested with Kpn I and BamH I and cloned into the pCAMBIA1300 vector, followed by rice transformation as described above [40]. The relative expression levels of OsNAC300 were determined in the transgenic OE lines with reverse transcription quantitative polymerase chain reaction (RT-qPCR).

Seeds of both wild-type rice (cv. Nipponbare) and OsNAC300 mutants were soaked in water for 2 days (d) before being transferred to a solution of $0.5 \mathrm{mM} \mathrm{CaCl}_{2}$. After $4 \mathrm{~d}$, seedlings were transferred into $\frac{1}{2}$ Kimura B solution ( $\left.\mathrm{pH} 5.5\right)$ and cultivated in a greenhouse maintained at 25 to $30{ }^{\circ} \mathrm{C}$. The composition of the nutrient solution was as follows: $0.18 \mathrm{mM}\left(\mathrm{NH}_{4}\right)_{2} \mathrm{SO}_{4}, 0.27 \mathrm{mM} \mathrm{MgSO} 4 \cdot 7 \mathrm{H}_{2} \mathrm{O}, 0.09 \mathrm{mM} \mathrm{KNO}_{3}, 0.18 \mathrm{mM} \mathrm{Ca}\left(\mathrm{NO}_{3}\right)_{2} \cdot 4 \mathrm{H}_{2} \mathrm{O}$, $0.09 \mathrm{mM} \mathrm{KH}_{2} \mathrm{PO}_{4}, 0.5 \mu \mathrm{M} \mathrm{MnCl} 2 \cdot 4 \mathrm{H}_{2} \mathrm{O}, 3 \mu \mathrm{M} \mathrm{H}_{3} \mathrm{BO}_{3}, 1 \mu \mathrm{M}\left(\mathrm{NH}_{4}\right)_{6} \mathrm{Mo}_{7} \mathrm{O}_{24} \cdot 4 \mathrm{H}_{2} \mathrm{O}, 0.4 \mu \mathrm{M}$ $\mathrm{ZnSO}_{4} \cdot 7 \mathrm{H}_{2} \mathrm{O}, 0.2 \mu \mathrm{M} \mathrm{CuSO} \cdot \cdot 5 \mathrm{H}_{2} \mathrm{O}$, and $20 \mu \mathrm{M}$ Fe(III)-EDTA. This solution was renewed every $2 \mathrm{~d}$. All the experiments were repeated at least three times.

\subsection{Subcellular Localization}

An OsNAC300 cDNA fragment was amplified from the rice cDNA library using a pair of OsNAC300-specific primers (Supplemental Table S1) and cloned into a pBluescript SK vector that harbored the $35 \mathrm{~S}$ cauliflower mosaic virus promoter [31]. An OsNAC300synthetic Green Fluorescent Protein (sGFP) fusion protein expression construct was transformed into onion epidermis cells using a gene gun (Bio-Rad Laboratories Inc., Hercules, CA, USA). After bombardment, the onion layers were incubated in the dark for $12-18 \mathrm{~h}$ at $25{ }^{\circ} \mathrm{C}$. Photographs were taken using laser confocal microscopy (UltraVIEW VOX, PerkinElmer, Waltham, MA, USA).

\subsection{Gene Expression Analysis}

Rice (cv. Nipponbare) was grown in a paddy field from mid-June to the end of September. To examine the expression pattern of OsNAC300, different tissues, including the roots, basal stems, old leaf blades, old leaf sheaths, new leaf blades, new leaf sheaths, flag leaf blades, flag leaf sheaths, node-Is, and seeds, were sampled at different stages of growth. To examine the OsNAC300 expression in response to Cd stress, 2-weekold wild-type rice seedlings were exposed to $C d(0-100 \mu \mathrm{M})$ for different time intervals. The roots were sampled for RNA extraction, with treatments conducted in triplicates. Total RNA $(1 \mu \mathrm{g})$ was used for first-strand cDNA synthesis using a HiScript II Q RT SuperMix Kit (Vazyme, Nanjing, China). RT-qPCR was performed using ChanQTM SYBR Color 
qPCR Master Mix (Vazyme). Actin (LOC_Os03g50885) was used as an internal standard. The primers for analysis of the gene expression are listed in Supplemental Table S1.

\section{4. $\beta$-glucuronidase (GUS) Staining}

The construction of OsNAC300 promoter-GUS was performed as previously described [31]. Primers listed in Supplemental Table S1 were used for the amplification of the promoter region. proOsNAC300::GUS was introduced into the Agrobacterium tumefaciens strain EHA105 and transformed into rice callus (Nipponbare) [40]. GUS staining of seedlings used $50 \mathrm{mM}$ sodium phosphate buffer ( $\mathrm{pH} 7.0)$ that contained $0.1 \%$ Triton X-100 $(v / v)$ and $0.5 \mathrm{mM}$ $\mathrm{X}$-Gluc (Sangon, Shanghai, China), which was incubated at $37^{\circ} \mathrm{C}$ for $6 \mathrm{~h}$. The stained tissues were observed using a Carl Zeiss laser scanning system (Zeiss, Oberkochen, Germany) and a Leica MZ95 stereomicroscope (Leica Instruments, Wetzlar, Germany).

\subsection{Phenotypic Analysis}

To compare the tolerance of OsNAC300 knockout lines and the wild-type rice to Cd stress, 2-week-old seedlings of the wild-type rice and three OsNAC300 knockout lines were exposed to a solution that contained $200 \mu \mathrm{M} \mathrm{CdCl}_{2}$ for $2 \mathrm{~d}$, and then $\mathrm{CdCl}_{2}$-free conditions were restored for 5 days. To observe the sensitivity of root elongation to $\mathrm{Cd}$ stress, 3-day-old rice seedlings were transferred to a solution that contained $0.5 \mathrm{mM} \mathrm{CaCl} 2$ (as control) or $5 \mu \mathrm{M} \mathrm{CdCl}_{2}+0.5 \mathrm{mM} \mathrm{CaCl}_{2}$ (as $+\mathrm{Cd}$ ) for 3 days. Daily elongation of the root was measured until day 3 of the $\mathrm{Cd}$ stress.

\subsection{Elemental Concentration Measurement}

The plants were grown on $1 / 2$ strength Kimura solution with $0.5,5$, or $50 \mu \mathrm{MCdCl}_{2}$ for 3 days, harvested, dried at $80^{\circ} \mathrm{C}$ for $3 \mathrm{~d}$, and then subjected to acid digestion. At least $0.2 \mathrm{~g}$ dry weight of tissue was used for each replicate; samples were digested with $\mathrm{HNO}_{3} / \mathrm{HClO}_{4}$ (87:13 [v/v]) at $100{ }^{\circ} \mathrm{C}$ for $1 \mathrm{~h}, 120^{\circ} \mathrm{C}$ for $1 \mathrm{~h}, 140{ }^{\circ} \mathrm{C}$ for $1 \mathrm{~h}, 160{ }^{\circ} \mathrm{C}$ for $1 \mathrm{~h}$, and $180{ }^{\circ} \mathrm{C}$ for $1 \mathrm{~h}$. After liquefying the processed samples in $2 \% \mathrm{HNO}_{3}$, the concentrations of $\mathrm{Cd}$ were determined using inductively coupled plasma mass spectrometry (ICP-MS, Perkin-Elmer NexION 300X, Waltham, MA, USA).

\subsection{RNA-Seq Analysis}

The seedlings of the wild type rice and the OsNAC300 knockout line (osnac300-1) were germinated and grown in culture solution for 2-weeks. The seedlings were treated with or without (as the controls) $100 \mu \mathrm{M} \mathrm{CdCl}_{2}$ for $12 \mathrm{~h}$. The seedling roots were sampled and rapidly frozen in liquid nitrogen for RNA extraction. There were 3 replicates in each group, 12 samples in total. Total RNA was extracted using an RNA extraction kit (TaKaRa, Dalian, China). The RNA quantity was determined using an ND-8000 spectrophotometer (Nanodrop Technologies, Inc., Wilmington, DE, USA), 1\% agarose gel electrophoresis, and a 2100-Bioanalyzer (Agilent Technologies, Santa Clara, CA, USA). RNA samples, in the final analysis, had been subjected to electrophoresis with no visible smears on agarose gels, with 260/280 ratios above 2.0, and RNA integrity numbers greater than 8.0 [35]. Total RNA samples of the roots were then sent to Genewiz Biotechnology Corporation (http:/ / www.genewiz.com.cn; Genewiz, Suzhou, China) for sequencing. The libraries were sequenced as 101-bp paired-end reads using an Illumina HiSeq2500 platform (Illumina, San Diego, CA, USA) according to the manufacturer's instructions. Sequence reads were mapped to the rice genome with combined gene annotation of RAPDB (http:/ / rapdb.dna.affrc.go.jp/download/archive/irgsp1/IRGSP1.0_representative_2013-04-24.tar.gz, IRGSP-1.0_predicted_2013-03-19.tar.gz) and MSU 7.0 (ftp:/ / ftp.plantbiology.msu.edu/pub/data/Eukaryotic_Projects/o_sativa/annotation_ $\mathrm{dbs} /$ pseudomolecules/version_7.0/all.dir/all.gff3) databases. The relative transcript abundance of each gene was measured in terms of the fragments per kilobase of transcript per million mapped reads (FPKM). The differential expression genes (DEGs) between the 
two sets of samples were identified using DESeq. The detailed bioinformatics analysis procedures can be found in our previous paper, He et al. [41].

To confirm the RNA-Seq results, we performed an RT-qPCR analysis of root RNA samples treated exactly the same way as described above. We examined the expression of the following genes: OsNAC300, OsPR10a, OsPR10b, RSOsPR10, JIOsPR10, OsPR5, OsPR1-71, and OsCHS1. Actin was used as an internal standard. The specific primers are listed in Supplemental Table S1. RNA-Seq data: Illumina reads of all samples were deposited in the Sequence Read Archive at the National Center for Biotechnology Information (http:/ / www.ncbi.nlm.nih.gov/sra) under accession number PRJNA622262.

\subsection{Transient Luciferase (LUC) Reporter Assay}

The 1184-bp, 1898-bp, and 1688-bp promoter regions of OsPR10a, OsPR10b, and OsCHS1 were amplified with their specific primer pairs, respectively (Supplemental Table S1). Three fragments were then cloned into the binary vector p1381Z-LUC to generate p1381ZproPR10a::LUC, p1381Z-proPR10b::LUC, and p1381Z-proCHS1 using the single BamH I restriction site, and the three constructs, including pCAMBIA1300-35S::OsNAC300, were subsequently mobilized into A. tumefaciens (strain EHA105). Transient luciferase reporter assays on 4-week-old Nicotiana benthamiana leaves were performed and checked. The relative expression level of LUC was quantified following transfection with different vectors. The hygromycin B resistance gene (HPTII redesignated as Hyg) was used for an internal standard based on its high and stable expression level under the same $35 \mathrm{~S}$ promoter. For this analysis, the relative expression level of LUC was measured by RT-qPCR from three biological replicates as previously described [42].

\subsection{ChIP-qPCR Assay}

A Chromatin Immuno-Precipitation Kit (Merck Millipore, Burlington, MA, USA) was used to perform ChIP-qPCR assays as previously described [43]. Briefly, approximately $2.5 \mathrm{~g}$ samples of 2-week-old 35S::NAC300-GFP transgenic rice seedlings were fixed with $50 \mathrm{~mL}$ of $1.0 \%$ formaldehyde under vacuum for $10 \mathrm{~min}$. Chromatin was extracted and sheared to 200- to 1000-bp fragments using ultrasonication. Then, $60 \mu \mathrm{L}$ of sheared DNA was immuno-precipitated with $4 \mathrm{mg}$ of anti-GFP antibody (Santa Cruz Biotechnology, Santa Cruz, CA, USA) overnight at $60 \mathrm{rpm}$ and $4{ }^{\circ} \mathrm{C}$. DNA fragments that were specifically associated with the OsNAC300 protein were released, purified, and used as templates for ChIP-qPCR. Genomic fragments from nonbinding sites were used as negative controls. Normalized relative expression was calculated by the ${ }^{\Delta \Delta} C_{t}$ (cycle threshold) method, and Actin in the "noAB" samples was used as the internal standard.

\subsection{Statistical Analysis}

Statistical analysis was performed using SPSS ver. 20.0 (IBM, Inc., Armonk, NY, USA) for all the data obtained. To compare the wild-type plants and osnac300 mutants, the data were analyzed using a one-way analysis of variance (ANOVA) followed by a Student's $t$-test or Tukey's test where appropriate. Data are shown as the means \pm SD as error bars.

\section{Results}

\subsection{Sequence and Subcellular Localization Analysis of OsNAC300}

The full-length open reading frame of OsNAC300 cloned from rice root cDNA was identical to the sequence in a rice sequence database (http://rapdb.dna.affrc.go.jp). OsNAC300 consists of two exons and one intron and encodes a protein of 396 amino acids with a calculated molecular mass of $43.86 \mathrm{kDa}$. Phylogenetic analysis showed that OsNAC300 is a member of the NAM subfamily of the rice NAC TF family (Supplemental Figure S1A). Among rice members, the closest homologs of OsNAC300 are OsNAC77L and OsNAC45, which share $70.82 \%$ and $66.75 \%$ identity, respectively, and belong to a subgroup (Supplemental Figure S1A). OsNAC45 plays complex roles by mediating the expression of development-related genes under various abiotic stresses in rice 
roots [44]. The OsNAC300 protein contains one conserved NAM domain for DNA binding (Supplemental Figure S1B). Using the ProtComp 9.0 program (http: / / www.softberry. $\mathrm{com} /$ ), we predicted that OsNAC300 is a nuclear protein with nuclear localization signal peptide (NLS).

To confirm the nuclear localization of OsNAC300, an OsNAC300-sGFP fusion construct was transiently expressed in the onion epidermal cells. Using confocal laser scanning microscopy, we found that the sGFP-tagged OsNAC300 signal was co-localized with the nuclear localization marker, red fluorescent protein-Histone 2A (RFP-H2A) [31], whereas, in cells that expressed solely sGFP, green fluorescence was observed throughout the cell (Figure 1). This result indicated that OsNAC300 is a nuclear-localized protein.

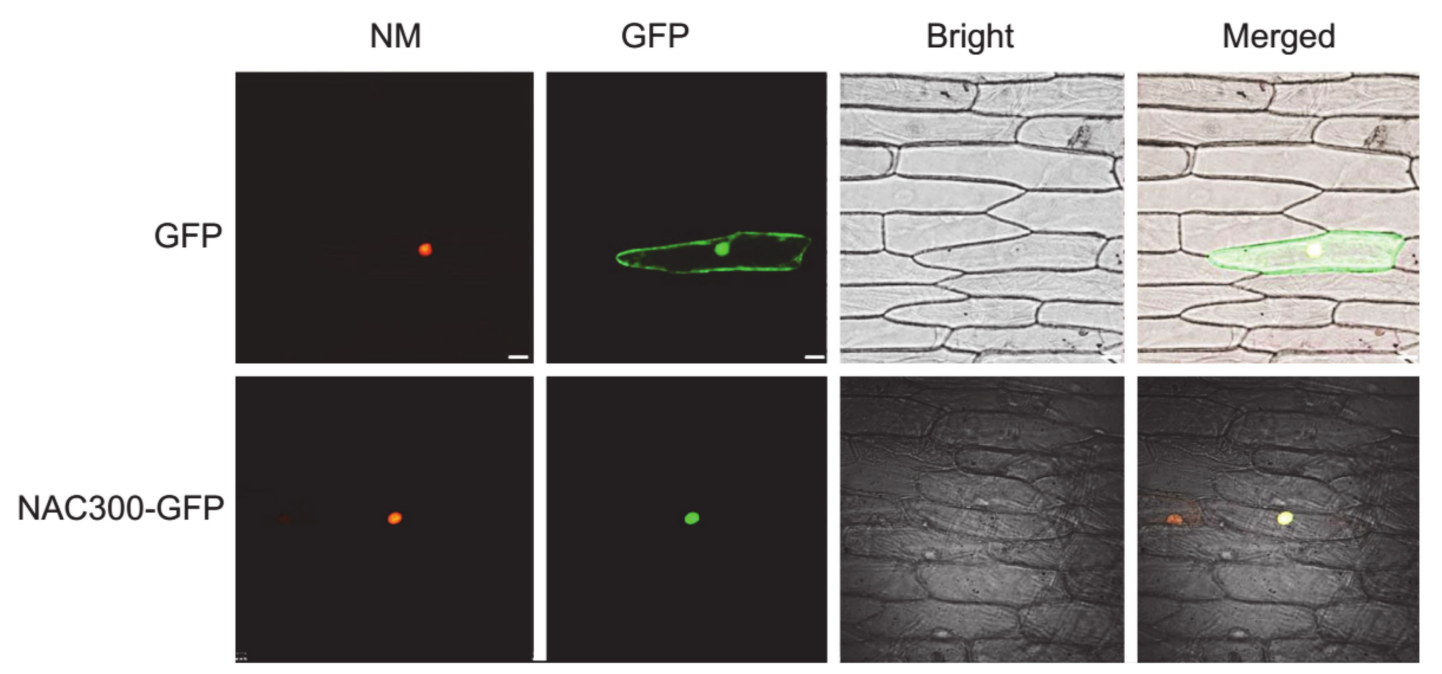

Figure 1. Subcellular localization of OsNAC300. Confocal images of onion epidermal cells expressing GFP, OsNAC300-GFP. RFP-H2A (red fluorescent protein Histone 2A); (nuclear marker, NM) is a nuclear localization tag. (Scale bars $=70 \mu \mathrm{m}$.)

\subsection{Expression Analysis of OsNAC300}

The expression pattern of OsNAC300 was investigated in rice plants grown in either soil or nutrient solution by using RT-qPCR. OsNAC300 was mainly expressed in the rice roots at all growth stages grown in a paddy field (Figure 2A). GUS staining analysis on the OsNAC300 promoter-GUS transgenic lines showed that OsNAC300 was primarily expressed in the primary and lateral roots (Figure $2 \mathrm{~B}-\mathrm{G}$ ), and was strongly induced by $\mathrm{Cd}$ stress (Figure 2H). Furthermore, RT-qPCR experiments showed that $\mathrm{Cd}$ stress induced the expression of OsNAC300 in the roots in a dose-dependent manner (Figure 2I). An analysis of the time-course assay of Cd-treated roots showed that the expression of OsNAC300 was rapidly upregulated in response to Cd stress from $6 \mathrm{~h}$ and reached its maximum at $24 \mathrm{~h}$ (Figure 2J). These results indicate that OsNAC300 was specifically expressed in roots and was induced by $\mathrm{Cd}$ stress. 


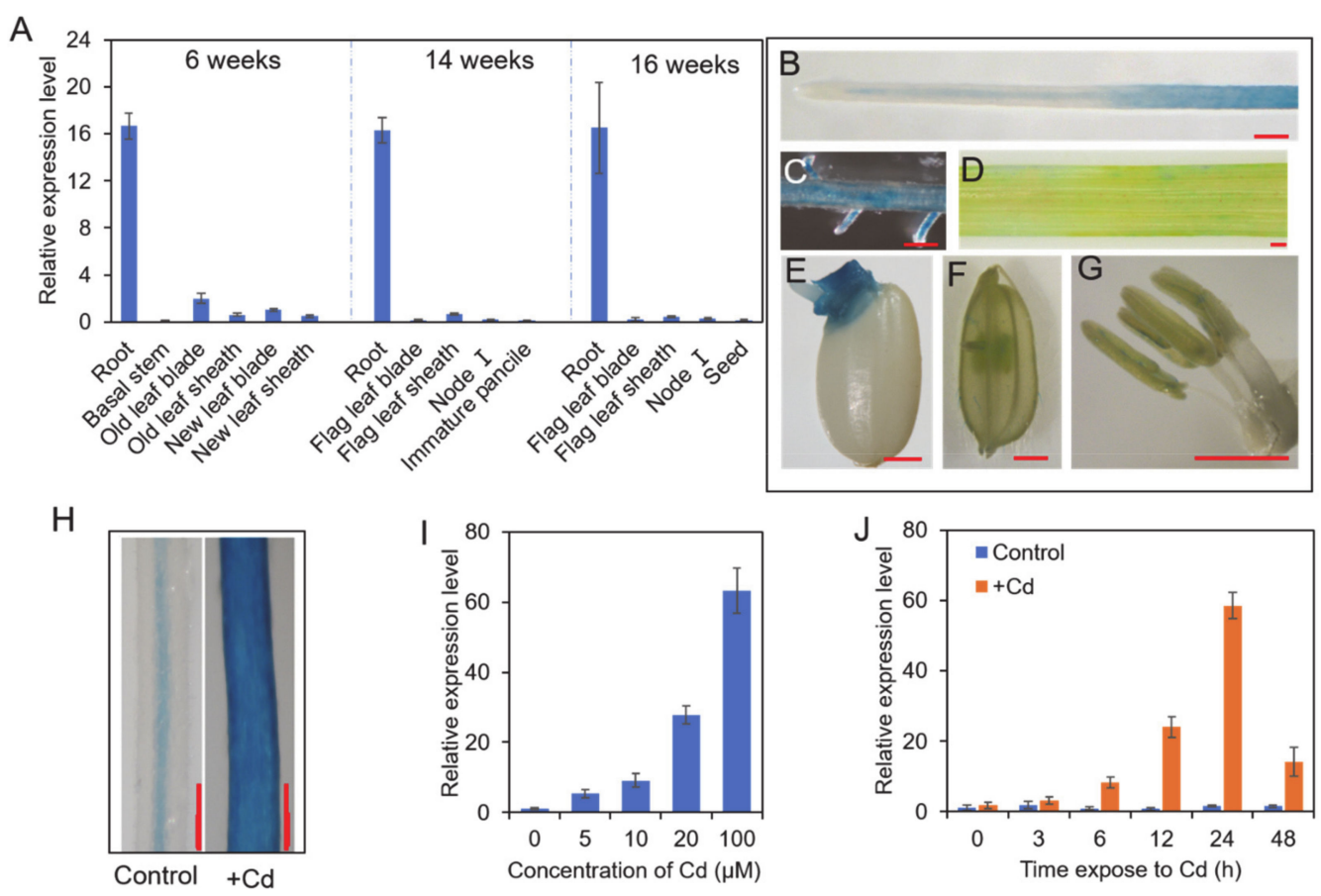

Figure 2. Expression pattern of OsNAC300. (A) Relative expression of OsNAC300 in various tissues at different growth stages. Samples of various organs were taken from rice grown in a paddy field. (B-H) $\beta$-glucuronidase (GUS) staining, bar $=1 \mathrm{~mm}$. (B) Region of primary roots (PR). (C) Region of lateral roots (LR). (D) Leaf. (E) Germinating seed. (F) Floret. (G) Stamen. (H) Region of PR under $-\mathrm{Cd}$ and $+\mathrm{Cd}(100 \mu \mathrm{M})$ for $24 \mathrm{~h}$. (I) Dose-dependent expression of OsNAC300 in the roots. Rice seedlings were exposed to a solution containing different concentrations of $\mathrm{CdCl}_{2}$ for 24 h. (J) Time-dependent expression of OsNAC300 in the roots. Rice seedlings were exposed to a solution containing $100 \mu \mathrm{M} \mathrm{CdCl}_{2}$ for different times. The expression of OsNAC300 was determined by reverse transcription quantitative polymerase chain reaction (RT-qPCR). Actin was used as an internal standard. Expression relative to seedlings without addition of Cd is shown. Data are means \pm SD of four biological replicates.

\subsection{Knock Out of OsNAC300 Enhances Sensitivity to Cd Stress}

To investigate the physiological role of OsNAC300 in Cd stress response and tolerance in rice, osnac300 knockout mutants were generated via CRISPR/Cas9. Three independent mutant lines (osnac300-1, osnac300-2, and osnac300-3) with nucleic acid deletions in the gRNA region were identified by sequencing (Supplemental Figure S2). Under control growth conditions without $\mathrm{Cd}$, no visible differences were observed between the wildtype plants and osnac300 knockout lines (Figure 3A). However, when grown in a solution containing $200 \mu \mathrm{M} \mathrm{Cd}^{2+}$ for 2 days and then transferred into a solution without $\mathrm{Cd}$ for 5 days' recovery, all of the three osnac 300 mutant plants withered and died, whereas the wild-type plants were still alive (Figure 3B). We observed necrosis and browning on the leaves of osnac300 mutants after 2 days of $\mathrm{Cd}$ treatment, which was not observed in the wild-type leaves (Figure 3C). The survival ratios of the three mutant lines were only 10, 12 , and $13 \%$ of that of the wild-type plants (Figure 3D). The daily elongation of the roots of the three osnac 300 mutants was also significantly less than that of the wild-type plants under Cd stress (Figure 3D). These results indicated that mutation of OsNAC300 enhances the sensitivity to $\mathrm{Cd}$ stress in rice, suggesting that OsNAC300 is required for Cd tolerance in rice. 

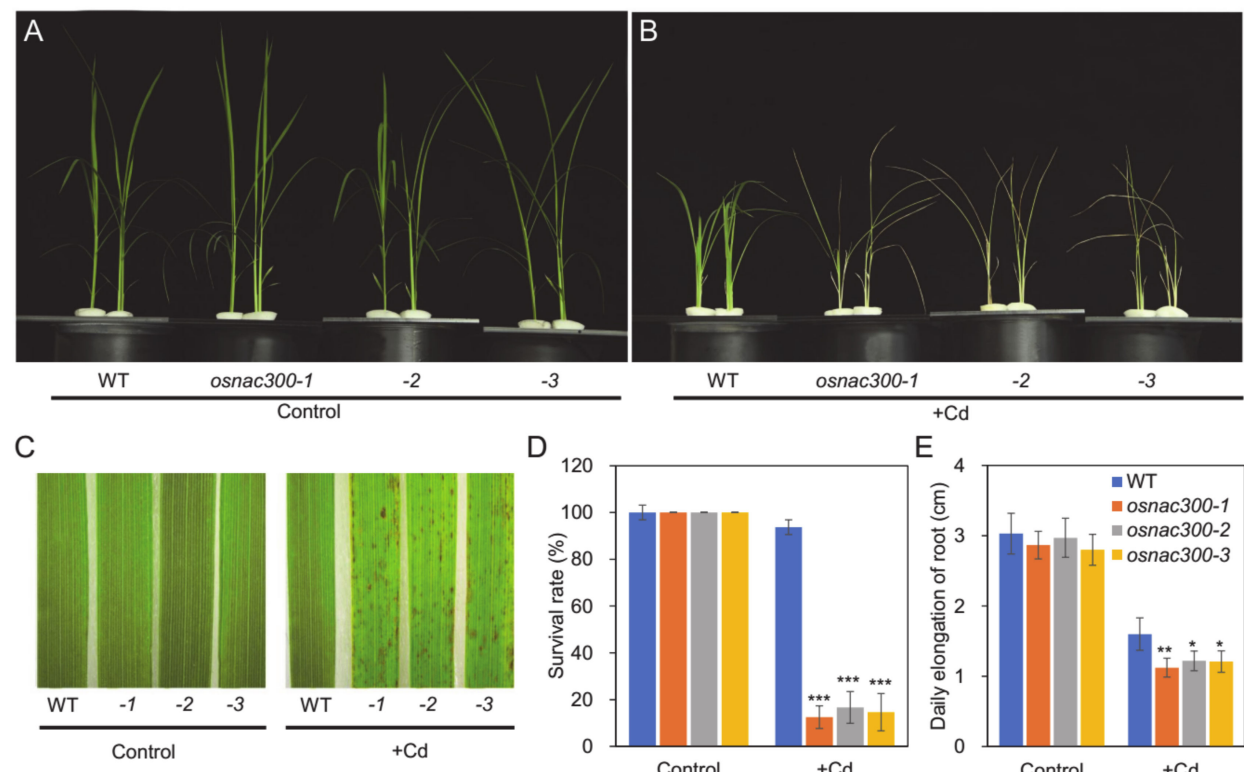

(1)
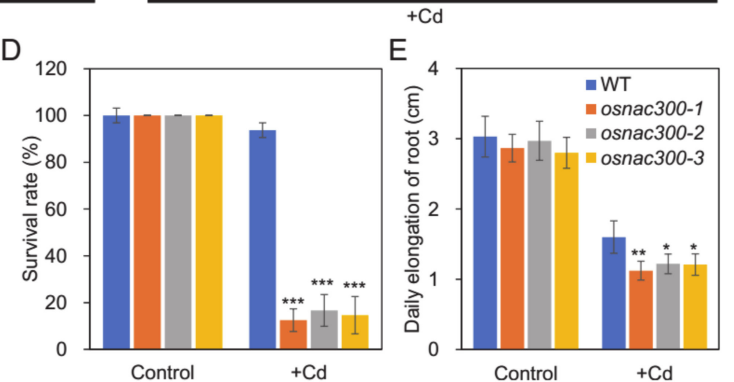

Figure 3. osnac300 mutants are hypersensitive to Cd stress. (A,B) Phenotype of osnac300 knockout lines subjected to Cd treatment. 2-week-old rice seedlings were grown on either control (1/2 Kimura solution) (A) or $+\mathrm{Cd}\left(+200 \mu \mathrm{M} \mathrm{CdCl}_{2}\right.$ in $1 / 2$ Kimura solution) (B) for 2 days, and subsequently restored in Cd-free solution for 5 days. (C) The images of leaves were taken when 2-week-old rice seedlings were grown under $200 \mu \mathrm{M} \mathrm{CdCl}_{2}$ for 2 days. (D) Survival rate of rice seedlings subjected to $\mathrm{Cd}$ treatments as described in (A). (E) Daily elongation of roots on the 3rd day of Cd stress. 3-d-old rice seedlings were grown on either control $\left(0.5 \mathrm{mM} \mathrm{CaCl}_{2}\right)$ or $+\mathrm{Cd}\left(5 \mu \mathrm{MCdCl}_{2}+0.5 \mathrm{mM} \mathrm{CaCl}_{2}\right)$ for 3 days. Mean values $\pm \mathrm{SD}$ are shown. The values of the indicated genotypes were compared to that of the wild-type (WT) plants (Student's $t$-tests, $\left.{ }^{* * *} p<0.001,{ }^{* *} p<0.01,{ }^{*} p<0.05, n=12\right)$.

To further investigate the function of OsNAC300, OsNAC300 overexpression lines were generated. The three lines OE1, OE2, and OE3 showed significantly higher (18.2, 15.8 , and 14.3 times) expression levels of OsNAC300 compared to the wild-type plants (Figure 4A). The daily root elongation of OsNAC300-OE lines (OE1, OE2, and OE3) was significantly higher than that of the wild-type plants in the presence of Cd (Figure 4B), whereas there was no significant difference between the wild-type plants and the overexpressing lines under control conditions. These results suggest that overexpression of OsNAC300 enhanced the tolerance to $\mathrm{Cd}$ in rice.
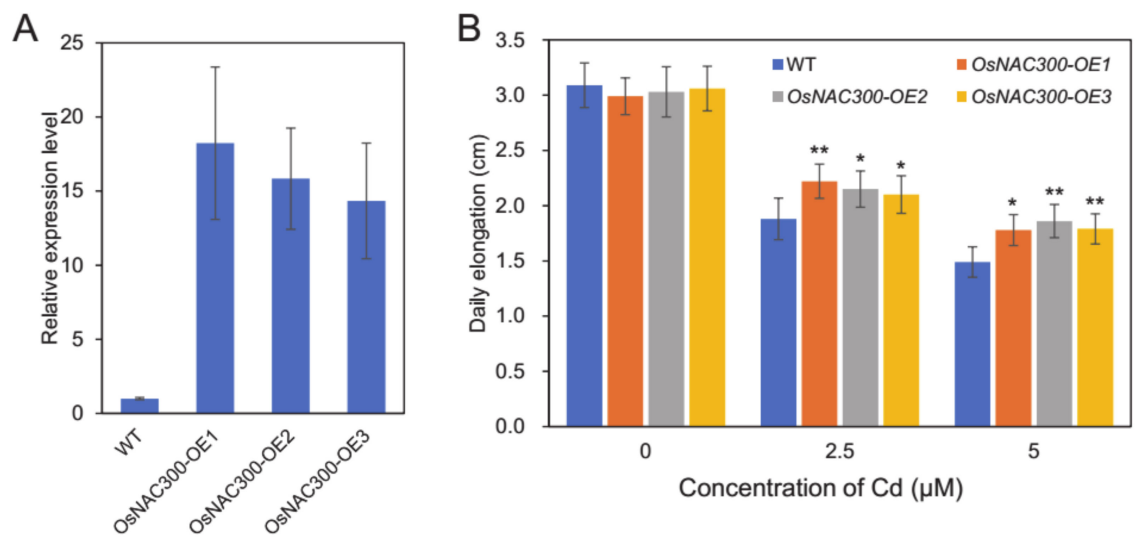

Figure 4. Overexpression of OsNAC300 enhanced the tolerance of rice roots to Cd. (A) RT-qPCR analysis of the relative transcription level of OsNAC300 in the roots of the wild-type (WT) and three OsNAC300 overexpression lines. (B) Daily elongation of roots on the $3^{\text {rd }}$ day of Cd stress. 3-d-old rice seedlings were grown on $0,2.5$ or $5 \mu \mathrm{M} \mathrm{CdCl}_{2}$ for 3 days. Mean values $\pm \mathrm{SD}$ are shown. The values of the indicated genotypes were compared to that of the WT (Student's $t$-tests, ${ }^{* *} p<0.01$, * $p<0.05, n=12$ ). 


\subsection{Role of OsNAC300 in the Accumulation of Cd in Rice}

To examine whether OsNAC300-mediated Cd tolerance is associated with the uptake and transport of $\mathrm{Cd}$ in rice, we grew osnac 300 knockout lines and the wild-type plants in a hydroponic solution with three different $\mathrm{Cd}$ concentrations for 3 days. There were no differences between the wild-type plants and osnac300 knockout lines in the concentration of $\mathrm{Cd}$ in both the roots and shoots under all three growth conditions (Figure 5A,B). Furthermore, the $\mathrm{Cd}$ accumulation in the roots and shoots of OsNAC300-overexpressing lines were also compared with the wild-type plants under the same conditions as above. Similarly, no differences were observed in the concentration of $\mathrm{Cd}$ in both roots and shoots between the wild-type plants and OsNAC300 overexpression lines under all conditions (Figure 5C,D). These results indicate that $\mathrm{Cd}$ accumulation or exclusion in rice is not significantly regulated by OsNAC300.
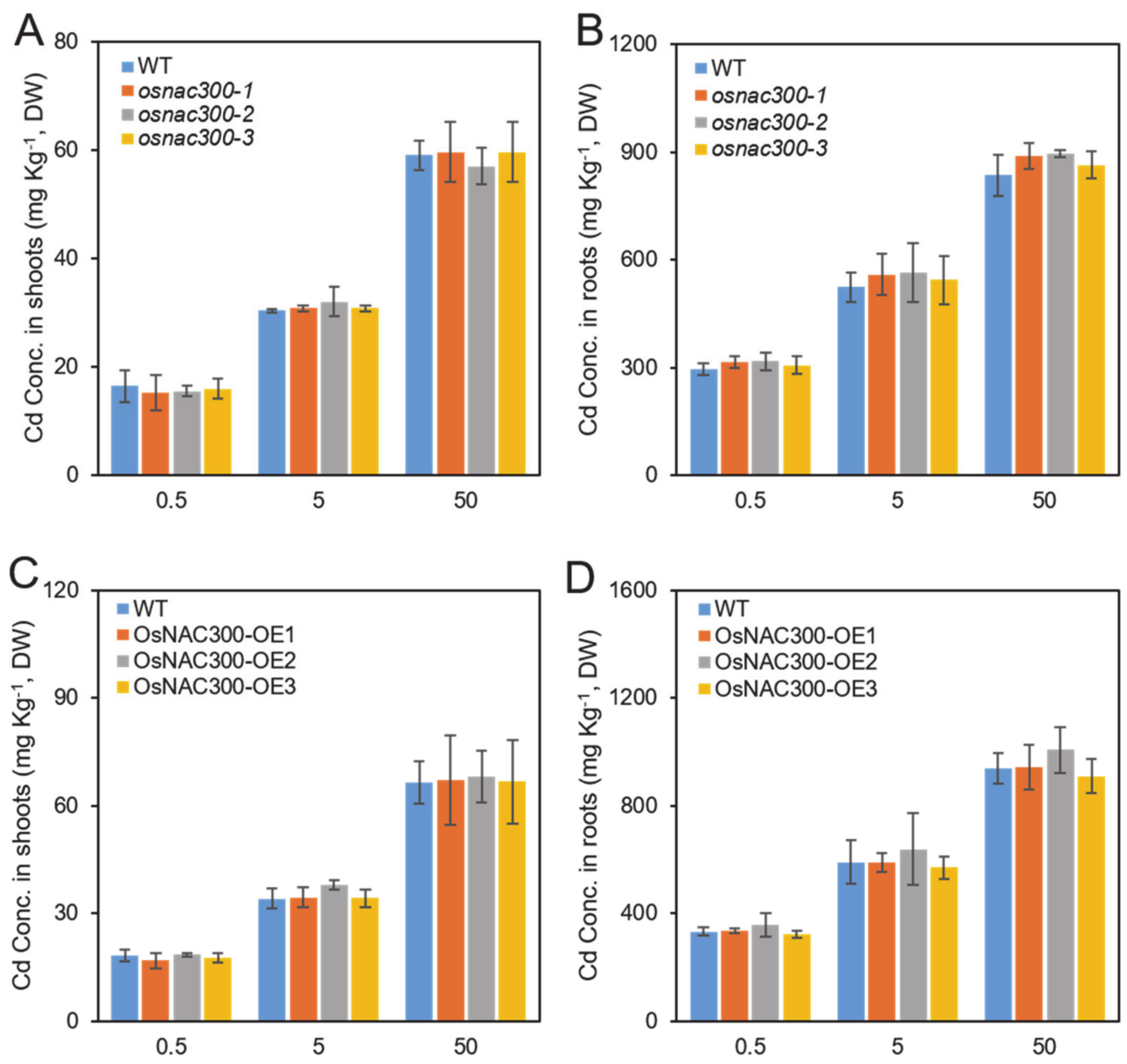

Figure 5. Cd concentrations of osnac300 mutants and overexpression lines. (A,B) Concentration of Cd in the shoots (A) and the roots (B) of osnac300 knockout lines. (C,D) Concentration of $\mathrm{Cd}$ in the shoots (C) and the roots (D) of osnac300 overexpression lines. 2-week-old rice seedlings were grown on $0.5,5$ or $50 \mu \mathrm{M} \mathrm{CdCl}_{2}$ for 3 days. The Cd concentration in the roots and shoots was determined by ICP-MS. Data are means \pm SD of four biological replicates. 
3.5. OsNAC300 Plays an Important Role in Changes in Global Gene Expression in Response to Cd Stress

To identify genes regulated by OsNAC300, we performed RNA-seq analysis using the wild-type plants and osnac300-1 mutant treated with or without Cd stress. A large number of differentially expressed genes (DEGs) were identified from the wild-type plants under Cd stress. Using $p \leq 0.01$ and fold change (FC) $\geq 1.5$ as a cutoff, 4443 and 3671 genes (Supplemental Tables S2 and S3) were identified as induced and repressed by Cd stress. The genes induced by Cd stress include many encoding TFs (OsNAC300, OsERF102, and OsERF104), defense-related proteins (OsPR10a, OsPR10b, and RSOsPR10), and many transporters (OsABCG1, OsABCG3, and OsABCG5). The genes repressed by Cd stress include many genes related to nutrient homeostasis, such as macronutrient metabolism (OsNAR2.1, OsNRT2.1, OsNRT2.2, and OsPT2), and micronutrient metabolism (OsNAS1/2/3, OsNAAT1, OsTOM1, OsZIP5, OsHMA2, and OsNramp5). Meanwhile, a total of 393 genes (256 upregulated and 137 downregulated genes) in the osnac300-1 mutant plants were identified as differentially expressed compared with the wild-type plants under normal conditions (Supplemental Tables S4 and S5).

Then, the Cd stress-induced genes that were affected by the loss of function of OsNAC300 were studied in more detail. 4227 of the $4443 \mathrm{Cd}$ stress-induced genes (e.g., OsDREB1B and OsDREB1C) were regulated normally in the osnac300-1 mutants (Supplemental Table S6). A total of 158 genes, such as OsERF4 and OsERF103, were hyperinduced in osnac300-1 mutants under +Cd conditions (Supplemental Table S7), suggesting that OsNAC300 could either directly or indirectly function as a repressor of these genes. Moreover, 58 genes were not induced (or induced to a lesser extent) in the osnac300-1 mutants compared with the wild-type plants under $+\mathrm{Cd}$ conditions (Supplemental Table S8). "Defense-related protein" was the most enriched biological process in the 58 genes, including OsCHS1, OsPR10a, and OsPR10b. These genes have been proposed to be involved in environmental stresses [14] and were deregulated in osnac300-1 mutants. These results indicated that OsNAC300 is either directly or indirectly involved in the activation of genes induced by Cd stress, including OsPR10a, OsPR10b, and OsCHS1.

\subsection{The Response of PR Genes and OsCHS1 to Cd Stress Are Dependent on OsNAC300}

To verify the OsNAC300-dependent Cd stress-induced expression of the $P R$ and OsCHS1 genes identified by RNA-seq, we performed RT-qPCR experiments. After Cd treatment, the expression levels of OsNAC300 in the roots of both the wild-type plants and mutants were upregulated approximately 20-fold (Figure 6A). This is consistent with those of the other RNA-Seq experiments [35], indicating that the effects of two Cd stress experiments are similar, and the expression of OsNAC300 that responds to Cd stress does not depend on its protein function. The expression of OsPR10a, OsPR10b, RSOsPR10, and JIOsPR10 was induced up to 470-, 25-, 60- and 4.3-fold by Cd stress in the roots of the wild-type, respectively (Figure 6B-E). However, in the roots of the osnac300-1 mutant, the expression levels of OsPR10a, OsPR10b, and RSOsPR10 were severely weakened (Figure 6B-E). The other two PR genes, OsPR5 and OsPR1-17, were also induced by Cd stress, dependent on OsNAC300 (Figure 6F,G). This showed that except for JIOsPR10, the expression of OsPR10a, OsPR10b, RSOsPR10, OsPR5, and OsPR1-71 that respond to Cd stress are dependent on OsNAC300. Chalcone synthase (CHS) is the rate-limiting enzyme in the flavonoid synthesis pathway. OsCHS1 in the wild-type plant roots was also induced by Cd stress. However, in the nac300-1 mutant roots, the expression of OsCHS1 was not affected by $\mathrm{Cd}$ stress (Figure 6H). 

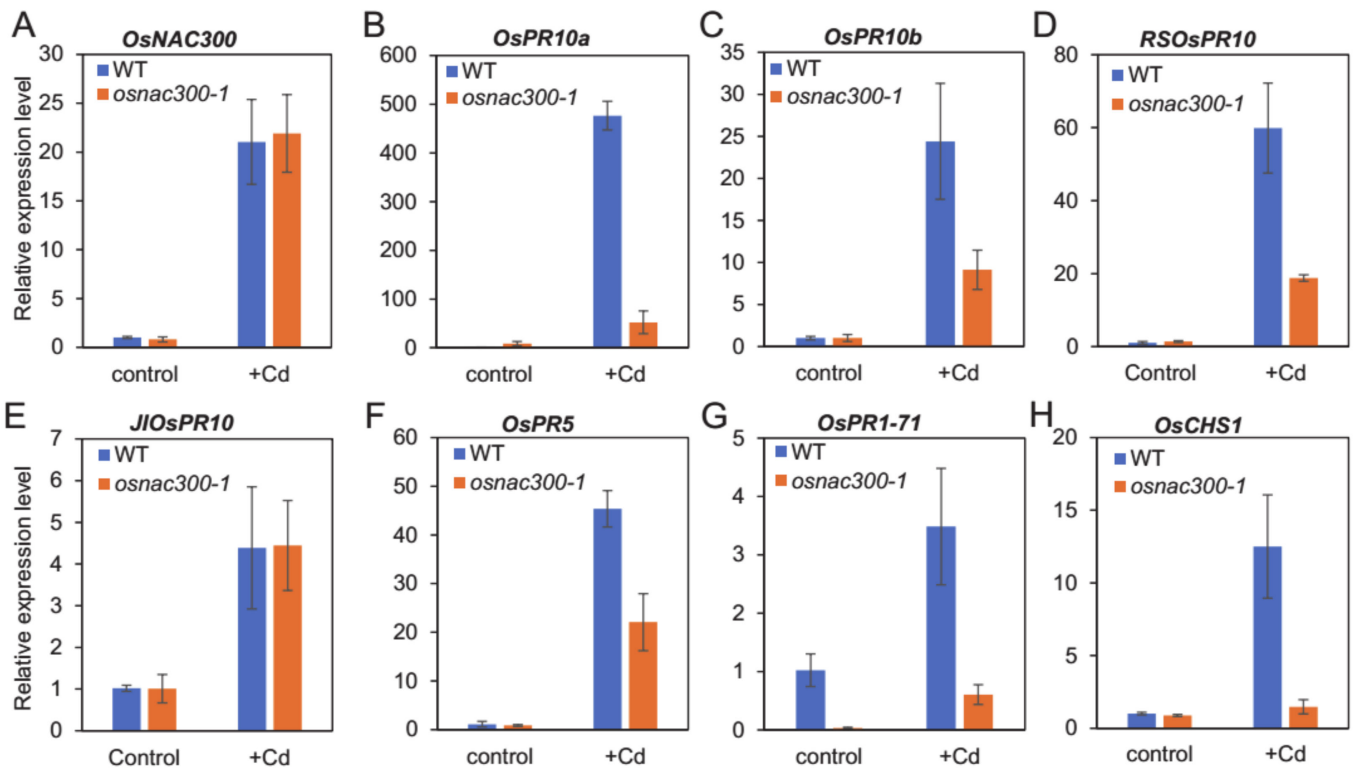

Figure 6. RT-qPCR analysis of potential downstream genes of OsNAC300 under Cd stress. The expression level of OsNAC300 (A), OsPR10a (B), OsPR10b (C), RSOsPR10 (D), JIOsPR10 (E), OsPR1-71 (F), OsPR5 (G), and OsCHS1 (H) in 2-week-old wild-type and osnac300-1 seedlings treated without or with $100 \mu \mathrm{M} \mathrm{CdCl}_{2}$ for $12 \mathrm{~h}$ assayed by RT-qPCR. The relative expression level was obtained by normalization to the expression level in the WT without Cd treatment. Actin was used as the internal standard. Data represent the mean $\pm \operatorname{SD}(n=4)$.

\subsection{OsNAC300 Directly Binds to the Promoters of OsCHS1, OsPR10a, and OsPR10b and Enhances Their Transcription}

Eleven genes that showed significantly lower levels of expression in the osnac300-1 line than in the wild-type plants under $\mathrm{Cd}$ stress and were highly induced by $\mathrm{Cd}$ stress (FC $\geq 3$ ) in the wild-type plants were selected for promoter analysis (Table 1) to verify their potential direct regulation relationship with OsNAC300. Bu et al. [45] reported that ANAC019 shows high affinity with the CATGTG motif. In our study, most of these genes (11 out of 14) contained one or more CATGTG motifs in their promoter (Supplemental Table S9). OsCHS1, OsPR10a, and OsPR10b contained one, two, and one CATGTG motifs in their promoters, respectively (Figure 7, Supplemental Table S9). This suggests that CATGTG motifs may play an important role in OsNAC300 response to Cd stress.

Table 1. Differential expression (in roots) of genes was affected by OsNAC300.

\begin{tabular}{|c|c|c|c|c|c|c|c|c|}
\hline \multicolumn{4}{|c|}{ WT } & \multicolumn{2}{|c|}{ osnac300-1 } & \multirow[b]{2}{*}{ FC } & \multirow[b]{2}{*}{ Symbol } & \multirow[b]{2}{*}{ Description } \\
\hline Gene ID & Control & $+\mathrm{Cd}$ & FC & Control & $+\mathrm{Cd}$ & & & \\
\hline \multicolumn{9}{|c|}{ pathogenesis-related protein } \\
\hline Os12g0555500 & 1.3 & 229.2 & 173.8 & 8.4 & 62.2 & 7.4 & OsPR10A & Probenazole-inducible protein PBZ1. \\
\hline Os12g0555200 & 19.3 & 253.9 & 13.2 & 16.2 & 78.0 & 4.8 & OsPR10B & $\begin{array}{l}\text { Similar to Probenazole-inducible } \\
\text { protein PBZ1. }\end{array}$ \\
\hline Os12g0555000 & 39.3 & 956.6 & 24.3 & 48.6 & 479.8 & 9.9 & - & $\begin{array}{l}\text { Similar to Probenazole-inducible } \\
\text { protein PBZ1. }\end{array}$ \\
\hline Os03g0663600 & 4.1 & 155.3 & 38.1 & 4.6 & 87.6 & 19.2 & - & $\begin{array}{l}\text { Similar to Pathogenesis-related } \\
\text { thaumatin-like protein. }\end{array}$ \\
\hline Os12g0628600 & 1.7 & 69.8 & 41.6 & 1.6 & 29.7 & 18.1 & OsPR5 & $\begin{array}{l}\text { Similar to Thaumatin-like } \\
\text { pathogenesis-related protein } 3 \text { precursor. }\end{array}$ \\
\hline \multicolumn{9}{|l|}{ Metabolism } \\
\hline Os11g0530600 & 0.4 & 3.9 & 9.2 & 0.4 & 0.5 & 1.3 & OsCHS1 & $\begin{array}{l}\text { Similar to Chalcone synthase C2 } \\
\text { (EC 2.3.1.74). }\end{array}$ \\
\hline
\end{tabular}


Table 1. Cont.

\begin{tabular}{|c|c|c|c|c|c|c|c|c|}
\hline \multicolumn{4}{|c|}{ WT } & \multicolumn{3}{|c|}{ osnac300-1 } & \multirow[b]{2}{*}{ Symbol } & \multirow[b]{2}{*}{ Description } \\
\hline Gene ID & Control & $+\mathrm{Cd}$ & FC & Control & $+\mathrm{Cd}$ & FC & & \\
\hline \multicolumn{9}{|c|}{ Other biology process } \\
\hline Os11g0514500 & 7.6 & 51.5 & 6.8 & 9.3 & 29.1 & 3.1 & - & $\begin{array}{l}\text { leucine-rich repeat-containing } \\
\text { extracellular glycoprotein precursor. }\end{array}$ \\
\hline Os03g0661600 & 19.7 & 74.7 & 3.8 & 24.6 & 46.9 & 1.9 & - & $\begin{array}{l}\text { Similar to Alpha-amylase/trypsin } \\
\text { inhibitor (Antifungal protein). }\end{array}$ \\
\hline \multicolumn{9}{|l|}{ Unknown } \\
\hline Os09g0272600 & 75.8 & 754.7 & 10.0 & 86.4 & 482.2 & 5.6 & - & Conserved hypothetical protein. \\
\hline Os10g0452100 & 11.1 & 50.5 & 4.5 & 15.0 & 32.3 & 2.2 & - & Conserved hypothetical protein. \\
\hline Os04g0653700 & 2.3 & 9.4 & 4.1 & 3.3 & 5.6 & 1.7 & - & Conserved hypothetical protein. \\
\hline
\end{tabular}

The locus identifiers are given for genes that are at least 3-fold upregulated in response to Cd in WT, are at least 1.5-fold downregulated in osnac300-1 Cd stress roots compared to WT Cd stress roots, and are 1.5-fold downregulated in fold change (FC) (osnac300-1 in +Cd) compared to FC (WT in $+\mathrm{Cd}$ ). 11 genes met these three requirements and were found to be statistically significant. WT and osnac300-1 signal intensities and fold changes are presented for the average of three biological replicates. Genes are grouped based on their regulation by OsNAC300 and secondly by predicted function.

A

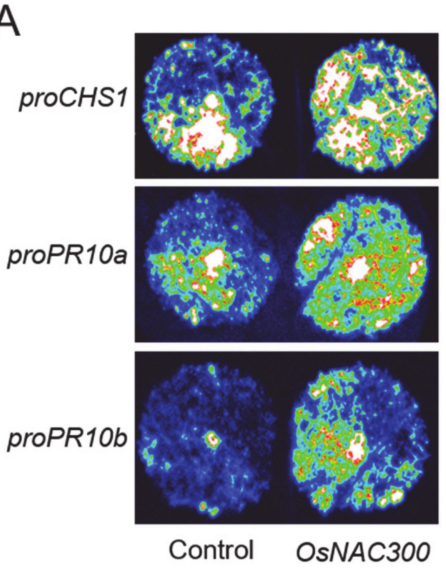

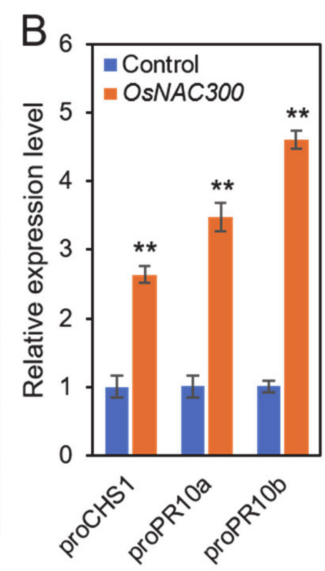

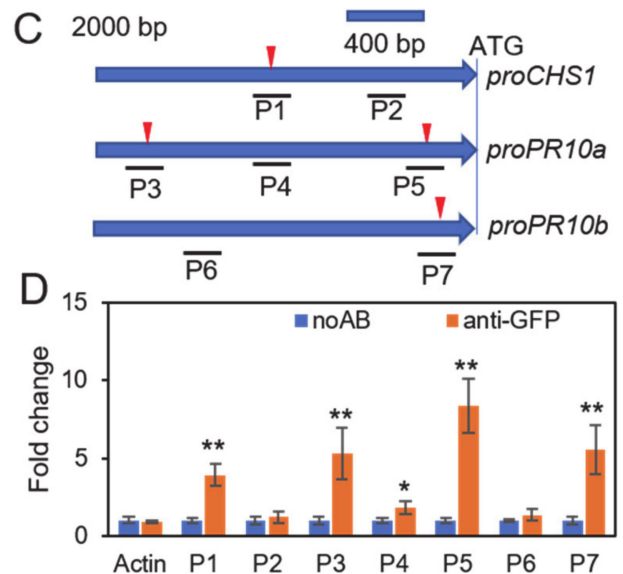

Figure 7. OsNAC300 directly binds to the promoters of OsCHS1, OsPR10a and OsPR10b, and enhances their transcription in tobacco leaves. (A) Luciferase signals were detected in leaf cells for $48 \mathrm{~h}$ following co-infiltration with empty vector and pCAMBIA1300-NAC300 and with p1381-proCHS1::LUC, p1381-proPR10a::LUC, and p1381-proPR10b::LUC. (B) The relative expression levels of luciferase were quantified by RT-qPCR following transfection with different vectors. Hyg was used for an internal standard (Student's $t$-test, ${ }^{* *} p<0.01$ ). Transient luciferase reporter assays show the activation of OsCHS1, OsPR10a, and OsPR10b expression by OsNAC300. Tobacco leaf transient expression assays using 1688-, 1184-, and 1898-bp promoter fragments of OsCHS1, OsPR10a, and OsPR10b, respectively. (C) Diagram of OsCHS1, OsPR10a, and OsPR10b promoters. Red wedge represents CATGTG motifs. P1-7 indicates genomic DNA fragments around the three promoters for ChIP-qPCR. (D) ChIP-qPCR assay. Binding of OsNAC300 to specific regions of the OsCHS1, OsPR10a, and OsPR10b promoters was examined with 4-week-old 35S::GFP-NAC300 transgenic seedlings. The noAB (no antibody) and a fragment of Actin were used as negative controls. Data are means $\pm \operatorname{SD}(n=4)$. Statistical comparison was performed by Tukey's multiple comparison test. Asterisks indicate significant differences from the control ${ }^{*} p<0.05$ and $\left.{ }^{* *} p<0.01\right)$.

To elucidate whether OsNAC300 could directly activate the promoter of these candidate genes, a luciferase (LUC) transient transcriptional activity assay was performed in tobacco leaves using the firefly LUC gene as a reporter, while OsNAC300, driven by the CaMV 35S promoter, served as an effector. Thus, 35S::OsNAC300 co-expression with the promoters of three genes (p1381-proCHS1::LUC, p1381-proPR10a::LUC, and p1381proPR10b::LUC) was observed to enhance the bioluminescence signal (Figure 7A), and the transcript abundance of LUC relative to that of the control was calculated (Figure 7B). This result indicated that OsNAC300 could directly enhance the transcriptional activ- 
ity of the promoters of the three genes and provided additional confirmation that the upregulation of these genes under Cd stress is dependent on OsNAC300.

The binding of TFs to cis-regulatory elements in the promoter region of their target genes is a key step to control their expression, and they can act as activators or repressors. To determine whether OsNAC300 binds to the native promoter that contains CATGTG motifs, ChIP-qPCR was used with the 35S::OsNAC300-GFP line in vivo. Seven fragments, spanning different regions of the OsCHS1, OsPR10a, and OsPR10b promoters (P1 to P7), were selected for qPCR analysis (Figure 7C). As indicated in Figure 7D, the fragments that contain CATGTG motifs (P1 for OsCHS1, P3 and P5 for OsPR10a, and P7 for OsPR10b) were considerably enriched compared with the negative controls. These results demonstrated that OsNAC300 binds to regions that contain the CATGTG motifs, such as the OsCHS1, OsPR10a, and OsPR10b promoters, thus controlling their levels of expression in response to Cd stress.

\section{Discussion}

Kusano et al. [38] reported that OsNAC300 was expressed in the root, shoot and flower, as well as in the mature phloem of vascular tissues at very early developmental stages, while via GUS staining and RT-qPCR we find that OsNAC300 was mainly expressed in roots but was only found at low levels in leaves (Figure 2A-G). Some previous studies showed that plant NAC TFs have roles in growth and development processes, particularly under biotic or abiotic stress conditions $[29,46,47]$. To our knowledge, this is the first report that NAC TF (OsNAC300) is very highly expressed in roots and strongly induced under $\mathrm{Cd}$ stress (Figure 2A,H-J). Its loss-of-function mutants are hypersensitive to $\mathrm{Cd}$ stress (Figure 3). In the OsNAC300-OE lines, the levels of NAC300 expression were higher than in the wild-type and roots exhibited an enhancement of tolerance to Cd toxicity (Figure 4A,B).

However, the mutation or overexpression of OsNAC300 did not affect the uptake and transport of $\mathrm{Cd}$ in rice (Figure 5C,D). This implies that under normal conditions or $\mathrm{Cd}$ stress, Cd uptake or efflux genes such as OsNramp5 [48], OsNramp1 [49], or OsABCG36 [50] are not downstream of OsNAC300. Besides, increasing the content of sulfhydryl-rich compounds, such as GSH and phytochelatin-PC, to enhance the tolerance of plant cells to $\mathrm{Cd}$ stress is typically accompanied by an increase in the content of $\mathrm{Cd}$ [6,51]. This also results in a hypothesis that OsNAC300 is not likely to regulate the PC-GSH pathway. The transcriptome data also revealed that the PC-GSH pathway is not regulated by OsNAC300 (Supplemental Tables S4 and S5).

Via the RNA-Seq analysis of rice roots, we identified the differential expression of genes that were affected by $\mathrm{Cd}$ stress in the osnac300 mutant compared with those in the wild-type plants (data are shown in Table 1). Although the expression of nutrition-related genes was inhibited by $\mathrm{Cd}$ stress, this process has nothing to do with the function of OsNAC300 (Supplemental Table S6, and Figure 8). This implies that OsNAC300 may improve the tolerance of rice to $\mathrm{Cd}$ stress by specifically regulating the expression of genes that encode resistance to stress. In this study, we found that four OsPR10 genes were induced by $\mathrm{Cd}$ stress in the rice genome, namely OsPR10a, OsPR10b, RSOsPR10, and JSOsPR10 (Table 1). Among these, OsPR10a was induced 500-fold, and OsPR10b was induced 25-fold (Figure 6B-E). Combined with the previous results, this study adds more detail to our knowledge that the OsPR10 gene family responds largely to stress conditions, i.e., both abiotic and biotic stresses [12]. PR10 genes might be used as a group of marker genes to show the degree of stress on the rice roots; this seems particularly likely for OsPR10a. Through gene knockout and RNA-Seq, we found that OsPR10a, OsPR10b, RSOsPR10, OsPR5, and OsPR1-71 responded to Cd stress, via dependence on OsNAC300. 


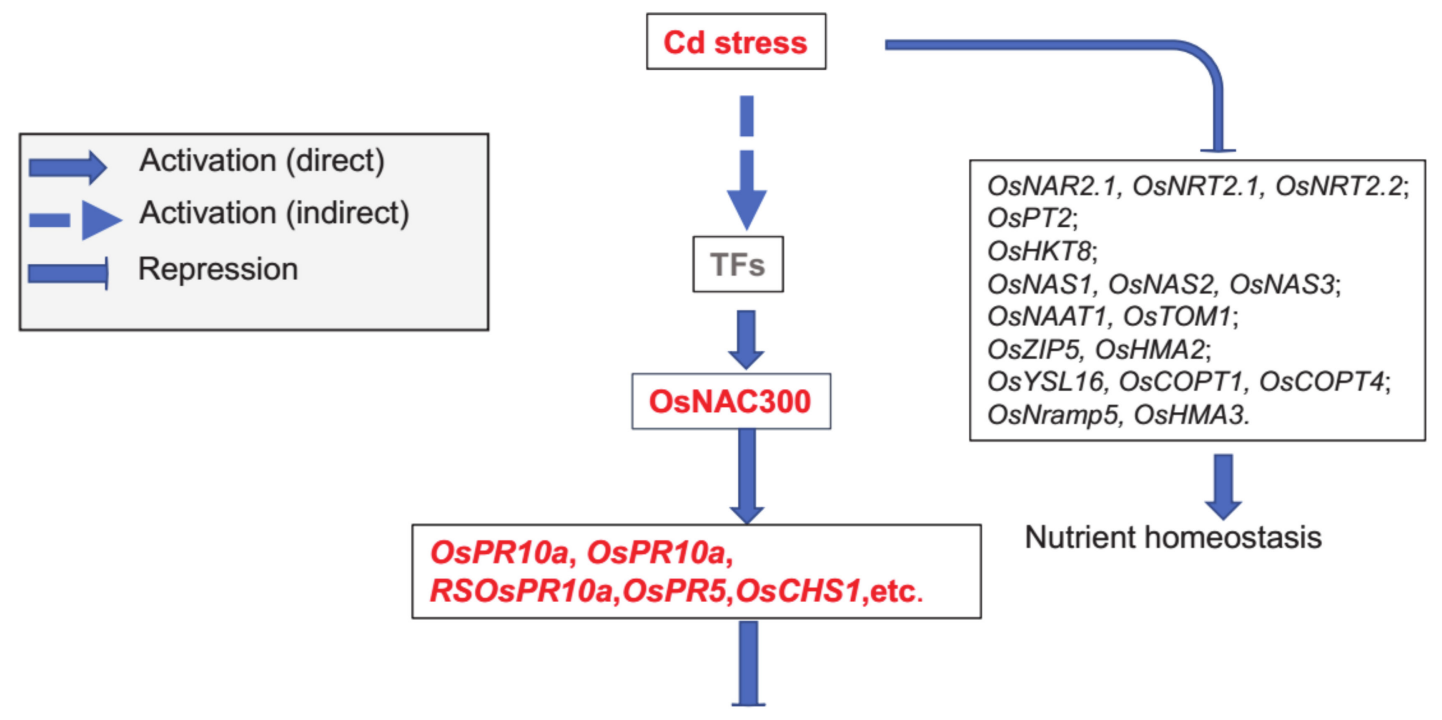

Abiotic / biotic stresses

Figure 8. The OsNAC300-dependent Cd stress response regulatory pathway in rice roots. In rice, the Cd stress signal activates downstream gene expression through OsNAC300-dependent and OsNAC300-independent regulatory pathways. In the OsNAC300-dependent regulatory pathway, OsNAC300 directly binds to promoter regions containing CATGT of Cd stress response genes, including OsPR10a, OsPR10b, and OsCHS1, which respond to abiotic and biotic stress. On the other hand, the Cd stress signal also regulates other nutrient homeostasis (e.g., OsNAR2.1, OsNRT2.1 and OsNRT2.2) that are not dependent on OsNAC300.

Additionally, confirmation of these findings was elaborated by performing a luciferase reporter assay and ChIP-qPCR experiments (as presented in Figure 7A-D). The ChIP-qPCR experiments demonstrated that OsNAC300 binds directly to the promoters of OsPR10a and OsPR10b (Figure 7D). This evidence indicates that OsPR10a and OsPR10b receive stress signals through OsNAC300. The loss of the OsNAC300 function does not affect the response of its own promoter to Cd stress (Figure 6A). This implies that there are other transcription factors upstream of OsNAC300 that regulate the expression of OsNAC300 in response to stress signals. The OsNAC300 homolog in Arabidopsis is a TF, i.e., AtNAC087, which was found to be expressed downstream of the master regulator AtORE1 during leaf senescence [52], while AtORE1(ANAC092) is itself an NAC domain TF factor [53]. Future studies on such interacting NAC TFs or others (yet to be known) in rice will precisely explain the stress signaling and regulatory mechanisms of OsNAC300.

OsCHS1 is a rate-limiting enzyme in the process of isoflavone synthesis [54]. Isoflavones play an important role in the antioxidant processes of plant cells [55]. In RNA-Seq, we found that OsCHS1 in the rice roots was significantly upregulated by Cd stress (Table 1 and Figure $6 \mathrm{H}$ ). We hypothesize that the rice root cells may synthesize more isoflavones by increasing the expression of OsCHS1, thereby enhancing their antioxidant capacity. In Arabidopsis, it was hypothesized that NAC TF-ANAC078 was involved in inducing the genes of flavonoid biosynthesis under conditions of high light stress [56]. The results of RNA-Seq and RT-qPCR showed that OsCHS1 is dependent on OsNAC300 in response to Cd stress. The ChIP-qPCR experiments enabled an observation that OsNAC300 binds directly to the OsCHS1 promoters. This evidence indicates that OsCHS1 receives stress signals through OsNAC300.

\section{Conclusions}

Taken together, we determined that OsNAC300 is a nuclear-localized TF that is highly expressed in the roots of rice. OsNAC300 plays an important role in the process of Cd stress tolerance in rice, and it directly regulates the levels of expression of OsPR10a, OsPR10b, and $\mathrm{OsCHS1}$ in response to Cd stress. 
Overall, as summarized in Figure 8, we conclude that OsNAC300 is an important regulator under stress. OsNAC300 may transmit stress signals in the roots, which provides new insights into the link between $\mathrm{Cd}$ stress and other stress response genes. However, further study will reveal new molecular insights for NAC TF and enhance our understanding to develop stress-tolerant crops.

Supplementary Materials: The following are available online at https:/ / www.mdpi.com/2073-439 5/11/1/95/s1. Figure S1. Phylogenetic analysis and multiple alignments of amino acid sequences of NAC family proteins in rice, Arabidopsis, tomato, maize. Supplemental Figure S2. Identification of osnac300 mutants generated by CRISPR/Cas9. Supplemental Table S1. Primers used in this study. Supplemental Table S2. Genes in WT induced by Cd stress (4443 genes). Supplemental Table S3. Genes in WT repressed by Cd stress (3671 genes). Supplemental Table S4. Gene expressed lower in osnac300-1 mutant than WT under control (137 genes). Supplemental Table S5. Genes expressed higher in osnac300-1 mutant than WT under control (256 genes). Supplemental Table S6. Genes normally expressed in osnac300-1 mutant under $+\mathrm{Cd}$ condition among $\mathrm{Cd}$ stress-induced genes (4227 genes). Supplemental Table S7. Genes expressed higher in osnac300-1 mutant than WT under $+\mathrm{Cd}$ among Cd stress-induced genes (158 genes). Supplemental Table S8. Gene expressed lower in osnac300-1 mutant than WT under $+\mathrm{Cd}$ among Cd stress-induced genes (58 genes). Supplemental Table S9. Motifs in 6 possible downstream genes of OsNAC300.

Author Contributions: L.Z., L.L., and S.H. conceived and designed the experiments; S.H., Y.S., K.I.S., H.X., and B.D. performed the experiments; collected, documented, and analyzed the data; S.H., and K.I.S. wrote the early draft; L.Z., J.X., and S.H. revised the manuscript, and all authors read and acknowledged the final form of the manuscript. All authors have read and agreed to the published version of the manuscript.

Funding: This work was supported by the National Key Research and Development Program of China (2016YFD0100700); the National Natural Science Foundation of China (31470347, 31770269 and 41907145); the China Postdoctoral Science Foundation (2018M632317); funding from State Key Laboratory for Conservation and Utilization of Subtropical Agro-bioresources (SKLCUSA-b201709).

Data Availability Statement: Illumina reads of all samples were deposited in the Sequence Read Archive at the National Center for Biotechnology Information (http:/ / www.ncbi.nlm.nih.gov/sra) under accession number PRJNA622262.

Conflicts of Interest: The authors affirm no conflicts of interests or any other concerns.

\section{References}

1. Clemens, S.; Aarts, M.G.M.; Thomine, S.; Verbruggen, N. Plant science: The key to preventing slow cadmium poisoning. Trends Plant Sci. 2013, 18, 92-99. [CrossRef] [PubMed]

2. Nawrot, T.; Plusquin, M.; Hogervorst, J.; Roels, H.A.; Celis, H.; Thijs, L.; Vangronsveld, J.; Van Hecke, E.; Staessen, J. Environmental exposure to cadmium and risk of cancer: A prospective population based study. Lancet Oncol. 2006, 7, 119-126. [CrossRef]

3. Wang, J.; Yu, N.; Mu, G.; Shinwari, K.I.; Shen, Z.; Zheng, L. Screening for Cd-safe cultivars of Chinese cabbage and a preliminary study on the mechanisms of Cd accumulation. Int. J. Environ. Res. Public Health 2017, 14, 395. [CrossRef] [PubMed]

4. Tsukahara, T.; Ezaki, T.; Moriguchi, J.; Furuki, K.; Shimbo, S.; Matsuda, I.N.; Ikeda, M. Rice as the most influential source of cadmium intake among general Japanese population. Sci. Total Environ. 2003, 305, 41-51. [CrossRef]

5. Dalcorso, G.; Farinati, S.; Furini, A. Regulatory networks of cadmium stress in plants. Plant Signal. Behav. 2010, 5, 663-667. [CrossRef] [PubMed]

6. Cobbett, C.S. Phytochelatins and their roles in heavy metal detoxification. Plant Physiol. 2000, 123, 825-832. [CrossRef] [PubMed]

7. Clemens, S. Molecular mechanisms of plant metal tolerance and homeostasis. Planta 2001, 212, 475-486. [CrossRef]

8. Luo, J.; Huang, J.; Zeng, D.; Peng, J.; Zhang, G.; Ma, H.; Guan, Y.; Yi, H.; Fu, Y.; Han, B.; et al. A defensin-like protein drives cadmium eux and allocation in rice. Nat. Commun. 2018, 9, 645. [CrossRef]

9. You, J.; Chan, Z. ROS regulation during abiotic stress responses in crop plants. Front. Plant Sci. 2015, 6, 1092. [CrossRef]

10. Koes, R.E.; Spelt, C.E.; Mol, J.N.M. The chalcone synthase multigene family of Petunia hybrida (V30): Differential, light-regulated expression during flower development and UV light induction. Plant Mol. Biol. 1989, 12, 213-225. [CrossRef]

11. Dao, T.T.H.; Linthorst, H.J.M.; Verpoorte, R. Chalcone synthase and its functions in plant resistance. Phytochem. Rev. 2011, 10, 397-412. [CrossRef] [PubMed]

12. Wu, J.; Kim, S.G.; Kang, K.Y.; Kim, J.G.; Park, S.R.; Gupta, R.; Kim, Y.H.; Wang, Y.; Kim, S.T. Overexpression of a pathogenesisrelated protein 10 enhances biotic and abiotic stress tolerance in rice. Plant Pathol. J. 2016, 32, 552-562. [CrossRef] 
13. Van Loon, L.C.; Rep, M.; Pieterse, C.M.J. Significance of inducible defense-related proteins in infected plants. Annu. Rev. Phytopathol. 2006, 44, 135-162. [CrossRef] [PubMed]

14. Liu, J.; Ekramoddoullah, A.K.M. The family 10 of plant pathogenesis-related proteins: Their structure, regulation, and function in response to biotic and abiotic stresses. Physiol. Mol. Plant Pathol. 2006, 68, 3-13. [CrossRef]

15. Lee, E.J.; Facchini, P. Norcoclaurine synthase is a member of the pathogenesis-related 10/Bet v1 protein family. Plant Cell 2010, 22 , 3489-3503. [CrossRef] [PubMed]

16. Xie, Y.; Chen, Z.; Brown, R.L.; Bhatnagar, D. Expression and functional characterization of two pathogenesis-related protein 10 genes from Zea mays. J. Plant Physiol. 2010, 167, 121-130. [CrossRef] [PubMed]

17. Takeuchi, K.; Gyohda, A.; Tominaga, M.; Kawakatsu, M.; Hatakeyama, A.; Ishii, N.; Shimaya, K.; Nishimura, T.; Riemann, M.; Nick, P.; et al. RSOSPR10 expression in response to environmental stresses is regulated antagonistically by jasmonate/ethylene and salicylic acid signaling pathways in rice roots. Plant Cell Physiol. 2011, 52, 1686-1696. [CrossRef] [PubMed]

18. McGee, J.D.; Hamer, J.E.; Hodges, T.K. Characterization of a PR-10 pathogenesis related gene family induced in rice during infection with Magnaporthe grisea. Mol. Plant-Microbe Interact. 2001, 14, 877-886. [CrossRef]

19. Jwa, N.S.; Kumar, A.G.; Rakwal, R.; Park, C.H.; Prasad, A.V. Molecular cloning and characterization of a novel jasmonate inducible pathogenesis-related class 10 protein gene, JIOsPR10, from rice (Oryza sativa L.) seedling leaves. Biochem. Biophys. Res. Commun. 2001, 286, 973-983. [CrossRef]

20. Hashimoto, M.; Kisseleva, L.; Sawa, S.; Furukawa, T.; Komatsu, S.; Koshiba, T. A novel rice PR10 protein, RSOsPR10, specifically induced in roots by biotic and abiotic stresses, possibly via the jasmonic acid signaling pathway. Plant Cell Physiol. 2004, 45, 550-559. [CrossRef]

21. Midoh, N.; Iwata, M. Cloning and characterization of a probenazole-inducible gene for an intracellular pathogenesis-related protein in rice. Plant Cell Physiol. 1996, 37, 9-18. [CrossRef] [PubMed]

22. Ryu, H.S.; Han, M.; Lee, S.K.; Cho, J.I.; Ryoo, N.; Heu, S.; Lee, Y.H.; Bhoo, S.H.; Wang, G.L.; Hahn, T.R.; et al. A comprehensive expression analysis of the WRKY gene superfamily in rice plants during defense response. Plant Cell Rep. 2006, $25,836-847$. [CrossRef] [PubMed]

23. Rakwal, R.; Agrawal, G.K.; Agrawal, V.P. Jasmonate, salicylate, protein phosphatase 2A inhibitors and kinetin up-regulate OsPR5 expression in cut responsive rice (Oryza sativa). J. Plant Physiol. 2001, 158, 1357-1362. [CrossRef]

24. Fang, Y.; You, J.; Xie, K.; Xie, W.; Xiong, L. Systematic sequence analysis and identification of tissue-specific or stress-responsive genes of NAC transcription factor family in rice. Mol. Genet. Genom. 2008, 280, 547-563. [CrossRef]

25. Yoon, Y.; Deok, H.S.; Shin, H.; Kim, H.J.; Kim, C.M.; Jang, G. The role of stress responsive transcription factors in modulating abiotic stress tolerance in plants. Agronomy 2020, 10, 788. [CrossRef]

26. Greve, K.; La Cour, T.; Jensen, M.K.; Poulsen, F.M.; Skriver, K. Interactions between plant RING-H2 and plant-specific NAC (NAM/ATAF1/2/CUC2) proteins: RING-H2 molecular specificity and cellular localization. Biochem. J. 2003, 371, 97-108. [CrossRef] [PubMed]

27. Nuruzzaman, M.; Sharoni, A.M.; Satoh, K.; Moumeni, A.; Venuprasad, R.; Serraj, R.; Kumar, A.; Leung, H.; Attia, K.; Kikuchi, S. Comprehensive gene expression analysis of the NAC gene family under normal growth conditions, hormone treatment, and drought stress conditions in rice using near-isogenic lines (NILs) generated from crossing Aday Selection (drought tolerant) and IR64. Mol. Genet. Genom. 2012, 287, 389-410. [CrossRef]

28. Sun, L.; Huang, L.; Hong, Y.; Zhang, H.; Song, F.; Li, D. Comprehensive analysis suggests overlapping expression of rice ONAC transcription factors in abiotic and biotic stress responses. Int. J. Mol. Sci. 2015, 16, 4306-4326. [CrossRef] [PubMed]

29. Yuan, X.; Wang, H.; Cai, J.; Bi, Y.; Li, D.; Song, F. Rice NAC transcription factor ONAC066 functions as a positive regulator of drought and oxidative stress response. BMC Plant Biol. 2019, 19, 278. [CrossRef] [PubMed]

30. Cohen, S.P.; Leach, J.E. Abiotic and biotic stresses induce a core transcriptome response in rice. Sci. Rep. 2019, 9, 6273. [CrossRef] [PubMed]

31. Hu, S.; Yu, Y.; Chen, Q.; Mu, G.; Shen, Z.; Zheng, L. OsMYB45 plays an important role in rice resistance to cadmium stress. Plant Sci. 2017, 264, 1-8. [CrossRef] [PubMed]

32. Chmielowska-Bak, J.; Gzyl, J.; Rucińska-Sobkowiak, R.; Arasimowicz-Jelonek, M.; Deckert, J. The new insights into cadmium sensing. Front. Plant Sci. 2014, 5, 245. [PubMed]

33. Chen, J.; Yang, L.; Yan, X.; Liu, Y.; Wang, R.; Fan, T.; Ren, Y.; Tang, X.; Xiao, F.; Liu, Y.; et al. Zinc-finger transcription factor ZAT6 positively regulates cadmium tolerance through the glutathione-dependent pathway in Arabidopsis. Plant Physiol. 2016, 171, 707-719. [CrossRef] [PubMed]

34. Hendrix, S.; Jozefczak, M.; Wójcik, M.; Deckers, J.; Vangronsveld, J.; Cuypers, A. Glutathione: A key player in metal chelation, nutrient homeostasis, cell cycle regulation and the DNA damage response in cadmium-exposed Arabidopsis thaliana. Plant Physiol. Biochem. 2020, 154, 498-507. [CrossRef]

35. He, F.; Liu, Q.; Zheng, L.; Cui, Y.; Shen, Z.; Zheng, L. RNA-Seq analysis of rice roots reveals the involvement of post-transcriptional regulation in response to cadmium stress. Front. Plant Sci. 2015, 6, 1136. [CrossRef]

36. Huang, Y.; Chen, H.; Reinfelder, J.R.; Liang, X.; Sun, C.; Liu, C.; Li, F.; Yi, J. A transcriptomic (RNA-seq) analysis of genes responsive to both cadmium and arsenic stress in rice root. Sci. Total Environ. 2019, 666, 445-460. [CrossRef]

37. Oono, Y.; Yazawa, T.; Kanamori, H.; Sasaki, H.; Mori, S.; Handa, H.; Matsumoto, T. Genome-wide transcriptome analysis of cadmium stress in rice. BioMed Res. Int. 2016, 9739505. [CrossRef] 
38. Kusano, H.; Asano, T.; Shimada, H.; Kadowaki, K.I. Molecular characterization of ONAC300, a novel NAC gene specifically expressed at early stages in various developing tissues of rice. Mol. Genet. Genom. 2005, 272, 616-626. [CrossRef]

39. Xie, K.; Yang, Y. RNA-Guided genome editing in plants using a CRISPR-cas9 system. Mol. Plant 2013, 6, 1975-1983. [CrossRef]

40. Ozawa, K. Establishment of a high efficiency Agrobacterium-mediated transformation system of rice (Oryza sativa L.). Plant Sci. 2009, 176, 522-527. [CrossRef]

41. Love, M.I.; Huber, W.; Anders, S. Moderated estimation of fold change and dispersion for RNA-seq data with DESeq2. Genome Biol. 2014, 15, 550. [CrossRef] [PubMed]

42. Guan, Q.; Yue, X.; Zeng, H.; Zhu, J. The protein phosphatase RCF2 and its interacting partner NAC019 are critical for heat stress-responsive gene regulation and thermotolerance in Arabidopsis. Plant Cell 2014, 26, 438-453. [CrossRef] [PubMed]

43. Saleh, A.; Alvarez, V.R.; Avramova, Z. An efficient chromatin immunoprecipitation (ChIP) protocol for studying histone modifications in Arabidopsis plants. Nat. Protoc. 2008, 3, 1018-1025. [CrossRef] [PubMed]

44. Yu, S.; Huang, A.; Li, J.; Gao, L.; Feng, Y.; Pemberton, E.; Chen, C. OsNAC45 plays complex roles by mediating POD activity and the expression of development related genes under various abiotic stresses in rice root. Plant Growth Regul. 2018, 84, 519-531. [CrossRef]

45. Bu, Q.; Jiang, H.; Li, C.B.; Zhai, Q.; Zhang, J.; Wu, X.; Sun, J.; Xie, Q.; Li, C. Role of the Arabidopsis thaliana NAC transcription factors ANAC019 and ANAC055 in regulating jasmonic acid-signaled defense responses. Cell Res. 2008, 18, 756-767. [CrossRef]

46. Nakashima, K.; Tran, L.S.P.; Van Nguyen, D.; Fujita, M.; Maruyama, K.; Todaka, D.; Ito, Y.; Hayashi, N.; Shinozaki, K.; Yamaguchi, S.K. Functional analysis of a NAC-type transcription factor OsNAC6 involved in abiotic and biotic stress-responsive gene expression in rice. Plant J. 2007, 51, 617-630. [CrossRef]

47. Song, S.Y.; Chen, Y.; Chen, J.; Dai, X.Y.; Zhang, W.H. Physiological mechanisms underlying OsNAC5-dependent tolerance of rice plants to abiotic stress. Planta 2011, 234, 331-345. [CrossRef]

48. Sasaki, A.; Yamaji, N.; Yokosho, K.; Ma, J.F. Nramp5 is a major transporter responsible for manganese and cadmium uptake in rice. Plant Cell 2012, 24, 2155-2167. [CrossRef]

49. Takahashi, R.; Ishimaru, Y.; Senoura, T.; Shimo, H.; Ishikawa, S.; Arao, T.; Nakanishi, H.; Nishizawa, N.K. The OsNRAMP1 iron transporter is involved in Cd accumulation in rice. J. Exp. Bot. 2011, 62, 4843-4850. [CrossRef]

50. Fu, S.; Lu, Y.; Zhang, X.; Yang, G.; Chao, D.; Wang, Z.; Shi, M.; Chen, J.; Chao, D.Y.; Li, R.; et al. The ABC transporter ABCG36 is required for cadmium tolerance in rice. J. Exp. Bot. 2019, 70, 5909-5918. [CrossRef]

51. Lee, K.; Bae, D.W.; Kim, S.H.; Han, H.J.; Liu, X.; Park, H.C.; Lim, C.O.; Lee, S.Y.; Chung, W.S. Comparative proteomic analysis of the short-term responses of rice roots and leaves to cadmium. J. Plant Physiol. 2010, 167, 161-168. [CrossRef] [PubMed]

52. Kim, H.J.; Hong, S.H.; Kim, Y.W.; Lee, I.H.; Jun, J.H.; Phee, B.K.; Rupak, T.; Jeong, H.; Lee, Y.; Hong, B.S.; et al. Gene regulatory cascade of senescence-associated NAC transcription factors activated by ETHYLENE-INSENSITIVE2-mediated leaf senescence signaling in Arabidopsis. J. Exp. Bot. 2014, 65, 4023-4036. [CrossRef] [PubMed]

53. Matallana-Ramirez, L.P.; Rauf, M.; Farage-Barhom, S.; Dortay, H.; Xue, G.P.; Dröge-Laser, W.; Lers, A.; Balazadeh, S.; Mueller-Roeber, B. NAC transcription factor ORE1 and Senescence-Induced BIFUNCTIONAL NUCLEASE1 (BFN1) constitute a regulatory cascade in Arabidopsis. Mol. Plant 2013, 6, 1438-1452. [CrossRef] [PubMed]

54. Shih, C.H.; Chu, H.; Tang, L.K.; Sakamoto, W.; Maekawa, M.; Chu, I.K.; Wang, M.; Lo, C. Functional characterization of key structural genes in rice flavonoid biosynthesis. Planta 2008, 228, 1043-1054. [CrossRef] [PubMed]

55. Hernández, I.; Alegre, L.; Van Breusegem, F.; Munné-Bosch, S. How relevant are flavonoids as antioxidants in plants? Trends Plant Sci. 2009, 14, 125-132. [CrossRef]

56. Morishita, T.; Kojima, Y.; Maruta, T.; Nishizawa-Yokoi, A.; Yabuta, Y.; Shigeoka, S. Arabidopsis NAC transcription factor, ANAC078, regulates flavonoid biosynthesis under high-light. Plant Cell Physiol. 2009, 50, 2210-2222. [CrossRef] 